\title{
RETRACTED
}

\section{Pre-treatment levels of circulating free IGF-I identify NSCLC patients who derive clinical benefit from figitumumab}

\section{A Gualberto*, , 2, ML Hixon², DD Karp ${ }^{3}$, D Li', S Green', M Dolled-Filhart ${ }^{4}$, LG Paz-Ares ${ }^{5}$, S Novello ${ }^{6}$, J Blakely CJ Langer ${ }^{8}$ and MN Pollak'}

'The Department of Clinical Development and Medical Affairs, Pfizer Oncology, New London, CT 06320, USA; ${ }^{2}$ Department of Pathology and Laboratory Medicine, Warren Alpert Medical School at Brown University, Providence, RI 02903, USA; ${ }^{3}$ Department of Thoracic Oncology, MD Anderson Cancer Center, Houston, TX 77030, USA; ${ }^{4}$ HistoRx Inc., New Haven, CT 065 II, USA; ${ }^{5}$ Department of Medical Oncology, Virgen del Rocio University Hospital, Seville 41013 , Spain; ${ }^{6}$ Department of Medical Oncology, University of Turin, Orbassano, Turin 10043, Italy; ${ }^{7}$ Department of Medical Oncology, West Clinic, Memphis, TN 38120, USA; ${ }^{8}$ Hematology/Oncology Division, Abramson Cancer Center, University of Pennsylvania, Philadelphia, PA 19104, USA; ${ }^{9}$ Department of Medical Oncology, McGill University, Montreal, Quebec H3T IE2, Canada

BACKGROUND: Phase III trials of the anti-insulin-like growth factor type I receptor (IGF-IR) antibody figitumumab (F) in unselected non-small-cell lung cancer (NSCLC) patients were recently discontinued owing to futility. Here, we investigated a role of free IGF- I (fGF-I) as a potential predictive biomarker of clinical benefit from $\mathrm{F}$ treatment.

MATERIALS AND METHODS: Pre-treatment circulating levels of flGF-I were tested in I I 0 advanced NSCLC patients enrolled in a phase II study of paclitaxel and carboplatin given alone (PC) or in combination with F at doses of 10 or $20 \mathrm{mg} \mathrm{kg}^{-1}$ (PCFI0, PCF20). RESULTS: Cox proportional hazards model interactions were between 2.5 and 3.5 for flGF-I criteria in the $0.5-0.9 \mathrm{ng} \mathrm{ml}^{-1}$ range. Patients above each criterion had a substantial improvement in progression-free survival on PCF20 related to PC alone. Free IGF- I correlated inversely with IGF binding protein I (IGFBP-I, $\rho=-0.295, P=0.005$ ), and the pre-treatment ratio of insulin to IGFBP-I was also predictive of $F$ clinical benefit. In addition, flGF-I levels correlated with tumour vimentin expression $(\rho=0.594, P=0.02 \mathrm{I})$ and inversely with E-cadherin $(\rho=-0.389, P=0.152)$, suggesting a role for flGF-I in tumour de-differentiation.

CONCLUSION: Free IGF-I may contribute to the identification of a subset of NSCLC patients who benefit from $F$ therapy. British Journal of Cancer (20II) I 04, 68-74. doi:I0.1038/sj.bjc.6605972 www.bjcancer.com Published online 23 November 2010

(c) 2011 Cancer Research UK

Keywords: IGF-IR; IGF-I; figitumumab; NSCLC

The insulin growth factor (IGF) system is comprised of the IGF ligands (IGF-1 and IGF-2), the IGF binding proteins (IGFBPs $1-7$ ) that regulate ligand bioactivity, the cell surface receptors insulinlike growth factor type 1 receptor (IGF-IR) and IGF-2R, the adaptor proteins insulin receptor substrate (IRS)-1 and -2 and downstream signalling pathways (Pollak, 2008). Signalling through the IGF-IR plays important roles in normal growth and development as well as in the initiation and progression of neoplasia (Chitnis et al, 2008). There is considerable current interest in targeting the IGF-1 receptor as a therapeutic strategy in oncology, with more than a dozen drug candidates undergoing clinical evaluation (Gualberto and Pollak, 2009). In NSCLC, the IGF-IR has been shown to be frequently expressed in tumour tissue as well as to mediate the proliferation of lung cancer cell lines (Favoni et al, 1994). Also, high IGF-1 levels have been associated with higher incidence and aggressiveness of NSCLC (Spitz et al,

*Correspondence: Dr A Gualberto; E-mail: antonio.gualberto@mpi.com or antonio_gualberto@brown.edu

Current address: Millennium: The Takeda Oncology Company, 35 Landsdowne Street, Cambridge, MA 02139, USA;

Received 26 July 2010; revised 4 October 2010; accepted 5 October 2010 ; published online 23 November 2010
2002). These data suggest that targeting the IGF-IR could be a viable approach for the treatment of NSCLC.

Figitumumab (F) is a selective inhibitor of the IGF-IR that has been well tolerated in initial studies (Gualberto, 2010). Figitumumab enhances the tumour growth inhibition of chemotherapy and targeted agents in pre-clinical models (Cohen et al, 2005). A recently completed phase II study concluded that $\mathrm{F}$ increases the response rate and progression-free survival (PFS) benefit of paclitaxel and carboplatin as first-line treatment of patients with advanced NSCLC (Karp et al, 2009). However, pivotal trials of this agent in NSCLC were recently discontinued owing to futility. These results stress the need to identify patient subpopulations that may preferentially benefit from $\mathrm{F}$ therapy. This paper summarises a series of preliminary ancillary studies conducted to characterise plasma markers that could identify a subset of patients who derive benefit from the addition of $F$ to standard NSCLC therapy.

\section{MATERIALS AND METHODS}

\section{Patients}

Study 1002 was a multiple-centre, open-label, randomised phase II trial that investigated the efficacy of the combination of $\mathrm{F}$ with 
paclitaxel (P) and carboplatin (C) as treatment for patients with chemotherapy-naïve stage IIIB or IV NSCLC (Karp et al, 2009). Briefly, patients had histologically or cytologically confirmed NSCLC not amenable to curative treatment. Eligible patients had at least one unidimensionally measurable lesion according to the Response Evaluation Criteria in Solid Tumours and Eastern Cooperative Oncology Group performance status of 0/1. Eligible patients were randomised 2:1 (PCF arm:PC arm) to receive $\mathrm{P}$ at $200 \mathrm{mg} \mathrm{m}^{-2}$ intravenously (i.v.) over $3 \mathrm{~h}$ and $\mathrm{C}$ with area under the plasma concentration-time curve of 6, i.v. over 15-60 min every 3 weeks with or without $\mathrm{F}$ at doses of 10 or $20 \mathrm{mg} \mathrm{kg}^{-1}$ in two sequential cohorts (PCF10, PCF20). The protocol was conducted in accordance with Good Clinical Practice guidelines and was approved by each participating institutional ethics review boards. All patients signed written informed consent before enrolment.

\section{Laboratory assessments}

Plasma samples were collected from fasted patients before trial treatments. Levels of total IGF-1, free IGF-1 (fIGF-1), IGF-2, IGFBP-1, IGFBP-2, IGFBP-3, insulin and cotinine were determined at a central laboratory (Department of Pathology and Laboratory Medicine, Brown University, Providence, RI, USA), using the ELISA method. Antibodies and reagents were from BeckmanCoulter Diagnostic System Laboratories (Webster, TX, USA) as follows: total IGF-1 (DSL 10-2800), fIGF-1 (DSL 10-9410), IGF-2 (DSL 10-2600), IGFBP-1 (DSL 10-7810), IGFBP-2 (DLS 10-7100), IGFBP-3 (DSL 10-6600) and insulin (DSL 10-1610). Cotinine was determined using a kit (CO096A) from Calbiotech (Spring Valley, CA, USA). Glucose and creatinine were determined at the local clinical study sites using standard techniques. E-cadherin and vimentin were quantified using fluorescent immunohistochemistry (F-IHC) and an automated analysis system. Briefly, tumour tissues were deparaffinised, hydrated in water and antigen retrieval performed using standard techniques. Incubation with primary antibodies was conducted for $1 \mathrm{~h}$ at room temperature. Primary antibodies were mouse anti-E-cadherin (M3612, clone NCH38, $2 \mu \mathrm{g} \mathrm{ml}^{-1}$; Dako, Carpinteria, CA, USA) and mouse anti-vimentin (MS-129, $0.07 \mu \mathrm{g} \mathrm{ml}^{-1}$; Thermo Scientific, Rockford, IL, USA). Each primary antibody was included in a cocktail with rabbit anti-pan-cytokeratin (Z0622, 1:200; Dako) for the identification of epithelial regions and non-nuclear regions. Image capture, review, validation and scoring were carried out using a PM2000 epi-fluorescence microscopy system and AQUAnalysis software (HistoRx, New Haven, CT, USA).

\section{Statistical analysis}

Progression-free survival curves were constructed using the Kaplan-Meier method, and differences analysed by the log-rank test using the MedCalc software (Mariakerke, Belgium). Receiveroperating characteristic (ROC) analysis, area under the curve estimates and significance tests were accomplished using the builtin functions of MedCalc. Cox proportional hazards regression analysis was used to determine biomarker interactions. Biomarker data were analysed using ANOVA and correlations determined using Pearson's correlation tests.

\section{RESULTS}

Pre-treatment plasma fIGF-1 levels identify NSCLC patients who may benefit from the addition of $\mathrm{F}$ to standard chemotherapy.

A total of 156 patients were randomised 2:1 to receive $P C$ with or without $\mathrm{F}$ at doses of 10 or $20 \mathrm{mg} \mathrm{kg}^{-1}$ (PC, PCF10, PCF20). Plasma samples were obtained on cycle 1 day 1 before dosing from 110 of these patients. Patients were $68 \%$ men and had a median age of 64 years (range: 36-85). Forty-nine percent of them had tumours of adenocarcinoma histology and $80 \%$ were stage IV. Thirty-five patients received PC, 40 PCF10 and 35 PCF20. The overall efficacy results of this trial have been reported previously (Karp et al, 2009). Patients receiving the PCF20 regimen had a clinical benefit in terms of PFS of approximately 6 weeks over PC alone, while no clinical benefit over that of PC alone was observed with PCF10 (3.53, 3.60, 5.0 months median PFS for PC, PCF10 and PCF20, respectively, $P=0.015)$. Median concentrations of baseline total IGF-1, free IGF-I, total IGF-2, insulin, and IGFBP-1, -2, -3 were, respectively, 219.3, 0.6, 578.1, 23.6, 15.1, 2.3 and $3627.8 \mathrm{ng} \mathrm{ml}^{-1}$. Potential biomarker associations with patient demographics were investigated. Higher baseline levels of fIGF-1 were observed in female patients $\left(0.78 \mathrm{ng} \mathrm{ml}^{-1}, 0.22-1.3895 \% \mathrm{CI}\right.$, $N=36)$ than in male patients $\left(0.52 \mathrm{ng} \mathrm{ml}^{-1}, 0.07-1.5095 \% \mathrm{CI}\right.$, $N=74, P=0.005)$, and in patients with tumours of adenocarcinoma histology $\left(0.76 \mathrm{ng} \mathrm{ml}^{-1}, 0.13-1.6895 \% \mathrm{CI}, N=53\right)$ than in those with other histologies $\left(0.55 \mathrm{ng} \mathrm{ml}^{-1}, 0.06-1.495 \% \mathrm{CI}\right.$, $P=0.03)$. No other differences were identified.

Progression-free survival was estimated in the subset of patients providing biomarker samples using the Kaplan-Meier method. Median PFS was similar to that in the overall trial population: 2.97 , 3.63 and 5.6 months, respectively, for the PC, PCF10 and PCF20 cohorts $(P=0.002)$. The ability of pre-treatment biomarker tests to identify patients who experienced prolonged clinical benefit on PCF treatment, for example, PFS longer than 6 months, was investigated using ROC analysis. Receiver operating characteristic curves plot the true positive rate (sensitivity) in function of the false positive rate (100-specificity, if expressed as percentage) at different biomarker cutoff points, and the $95 \%$ CI of the value for the area under the ROC curve (AUC) can be employed to test for predictive value (ROC curve AUC must be $>0.5$ for the test to be potentially useful) (Zweig and Campbell, 1993). Receiver operating characteristic plots were also employed to screen for markers able to identify patients with reduced clinical benefit, for example, patients with PFS shorter than 3 months. Table 1 summarises the AUC values and significance of the ROC analyses for the baseline analytes of patients receiving PCF20. As expected, the AUC $95 \%$ CI were wide owing to the small sample size $(N=35)$; however, it was observed that high pre-treatment levels of fIGF-1 (at least $0.54 \mathrm{ng} \mathrm{ml}^{-1}$ ) in patients receiving PCF20 were associated $(P=0.007)$ with PFS $>6$ months, whereas low pre-treatment fIGF-1 levels were associated $(P=0.026)$ with PFS $<3$ months. When patients receiving PCF10 and PCF20 were analysed together $(N=75)$, significant AUCs $(\mathrm{P} \leqslant 0.05)$ were also identified. Figure 1 shows the ROC plots for all patients treated with $\mathrm{F}\left(10,20 \mathrm{mg} \mathrm{kg}^{-1}\right)$ using PFS benefit beyond 3, 4, 5 and 6 months as end points.

Table I ROC for baseline IGF-IR-related serum analytes in patients receiving PCF20

\begin{tabular}{|c|c|c|c|c|}
\hline \multirow[b]{2}{*}{ Analyte } & \multicolumn{2}{|c|}{ PFS at 3 months } & \multicolumn{2}{|c|}{ PFS at 6 months } \\
\hline & $\begin{array}{c}\text { ROC AUC } \\
95 \% \mathrm{Cl}\end{array}$ & $P$-value & $\begin{array}{c}\text { ROC AUC } \\
95 \% \mathrm{Cl}\end{array}$ & $P$-value \\
\hline Total IGF-I & $0.368-0.758$ & 0.566 & $0.476-0.846$ & 0.140 \\
\hline flGF-I & $0.536-0.852$ & 0.026 & $0.661-0.933$ & 0.007 \\
\hline IGF-2 & $0.430-0.811$ & 0.290 & $0.460-0.834$ & 0.215 \\
\hline Insulin & $0.387-0.769$ & 0.457 & $0.464-0.832$ & 0.213 \\
\hline IGFBP-I & $0.531-0.880$ & 0.040 & $0.405-0.784$ & 0.401 \\
\hline IGFBP-2 & $0.498-0.862$ & 0.086 & $0.361-0.752$ & 0.650 \\
\hline IGFBP-3 & $0.306-0.652$ & 0.842 & $0.478-0.809$ & 0.178 \\
\hline
\end{tabular}

Abbreviations: $A \cup C=$ area under the $\mathrm{ROC}$ curve; $\mathrm{Cl}=$ confidence interval; IGF = insulin-like growth factor; flGF-I =free insulin-like growth factor I; IGFBP = insulin-like growth factor binding protein; IGF-IR = insulin-like growth factor type I receptor; PCF = paclitaxel and carboplatin in combination with figitumumab; $\mathrm{PFS}=$ progression-free survival; $\mathrm{ROC}=$ receiver operating characteristics. 


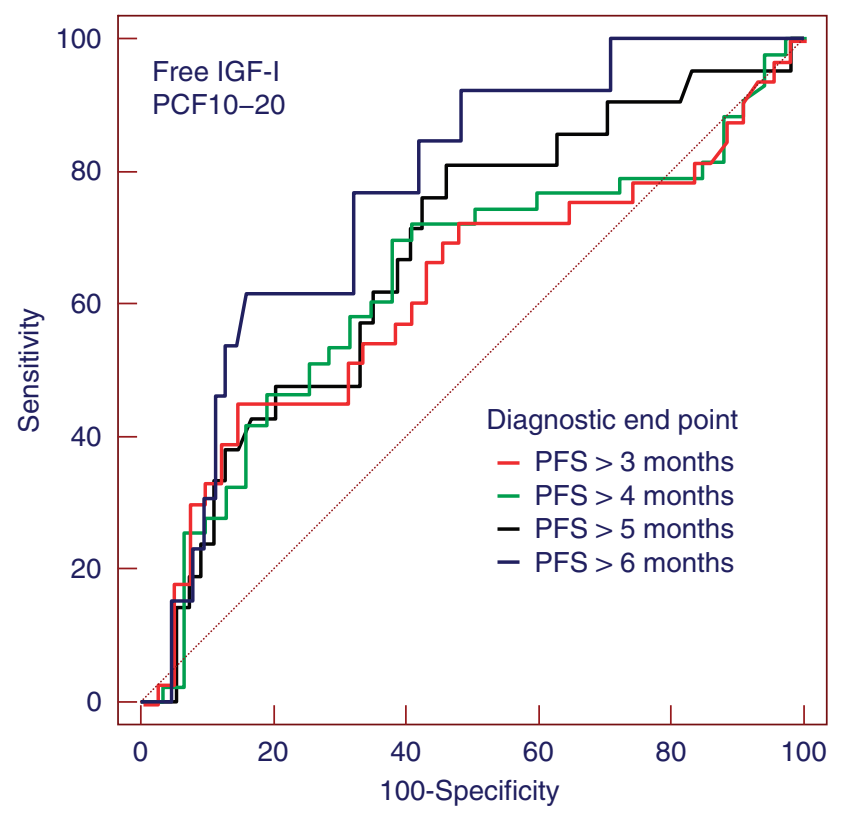

Figure I Receiver-operating characteristic curves for flGF-I as a predictive maker for PFS benefit at 3-6 months in PCF-treated patients $\left(10-20 \mathrm{mg} \mathrm{kg}^{-1} \mathrm{~F}\right)$.

Although our sample size was insufficient to investigate differences in AUC, the results represented in the figure were suggestive that fIGF-1 is a better predictor of long-term clinical benefit of $F$ combination therapy. In contrast, pre-treatment fIGF-1 levels were not predictive of PFS in patients receiving PC only (not shown), suggesting that this parameter was not a general prognostic marker for the outcome of chemotherapy. Of interest, high pre-treatment levels of IGFBP-1 were associated $(P=0.04)$ with PFS $<3$ months (Table 1).

The potential interaction between pre-treatment fIGF-1 criteria and the PFS benefit derived from $F$ treatment was then investigated using the Cox proportional hazards models. Free IGF-1 cutoff criteria from 0.1 to $0.9 \mathrm{ng} \mathrm{ml}^{-1}$ were examined. Useful criteria were found in the range of $0.5-0.9 \mathrm{ng} \mathrm{ml}^{-1}$. For PCF20 vs PC, the estimated treatment-biomarker interaction terms from Cox proportional hazards models were between 2.5 and 3.5 for fIGF-1 criteria in the $0.5-0.9 \mathrm{ng} \mathrm{ml}^{-1}$ range, with one-sided $P$-values of $0.11\left(0.5 \mathrm{ng} \mathrm{ml}^{-1}\right.$ criterion), $0.09\left(0.6 \mathrm{ng} \mathrm{ml}^{-1}\right.$ criterion $), 0.030$ $\left(0.7 \mathrm{ng} \mathrm{ml}^{-1}\right.$ criterion), $0.033\left(0.8 \mathrm{ng} \mathrm{ml}^{-1}\right.$ criterion) and 0.026 $\left(0.9 \mathrm{ng} \mathrm{ml}^{-1}\right.$ criterion) adjusted for multiple testing. Hazard ratios for patients with fIGF-1 values above or below the $0.5-0.9 \mathrm{ng} \mathrm{ml}^{-1}$ criteria are shown in Figure 2A. Patients above each criterion had a substantial observed improvement in PFS on the PCF20 arm, while only a modest effect was observed below the criterion. For example, the PFS hazard ratio (PCF20/PC) was 4.2 for patients with fIGF-1 above $0.8 \mathrm{ng} \mathrm{ml}^{-1}$, but only 1.9 for patients with fIGF-1 equal or below $0.8 \mathrm{ng} \mathrm{ml}^{-1}$. A significant biomarker/treatment interaction for PCF10 was only observed at the fIGF-1 $>0.8 \mathrm{ng} \mathrm{ml}^{-1}(P=0.027)$ and $>0.9 \mathrm{ng} \mathrm{ml}^{-1}(P=0.04)$ criteria. Figure $3 \mathrm{~A}-\mathrm{C}$ shows specific examples of Kaplan-Meier curves for all patients in the biomarker cohort (Figure 3A; $N=110$ ), those with a baseline fIGF-1 level equal or lower than $0.7 \mathrm{ng} \mathrm{ml}^{-1}$ (Figure 3B; $N=64$ ) and those with a baseline fIGF-1 level higher than $0.7 \mathrm{ng} \mathrm{ml}^{-1}$ (Figure 3B; $N=46$ ). Median PFS for patients who had a baseline fIGF-1 level above $0.7 \mathrm{ng} \mathrm{ml}^{-1}$ were $2.63(\mathrm{PC}), 3.97$ (PCF10) and 6.53 months (PCF20), respectively $(P=0.0007)$. In contrast, no apparent differences in median PFS between the treatment cohorts were observed in those who had a baseline fIGF-1 level equal or below $0.7 \mathrm{ng} \mathrm{ml}^{-1}$. Additional analysis of PFS
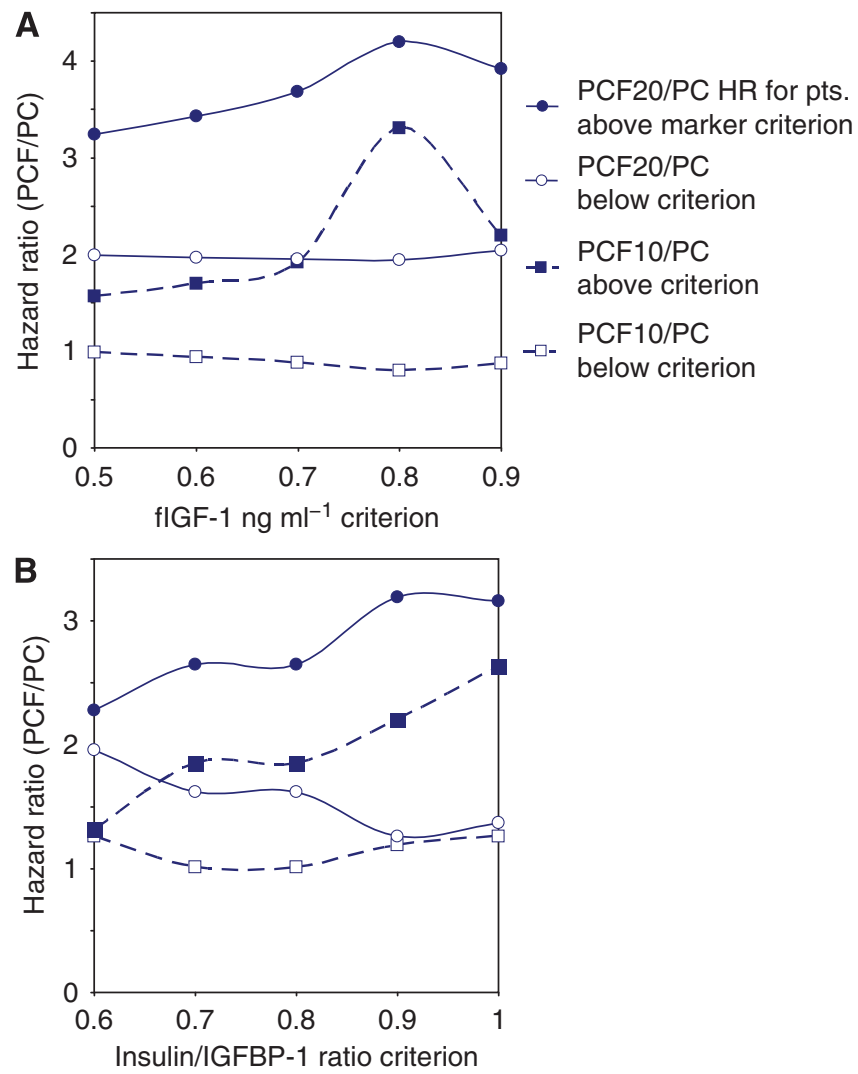

Figure 2 (A) Hazard ratio of Study 1002 patients receiving treatment with PCF (I0 or $20 \mathrm{mg} \mathrm{kg}^{-1}$ ) vs PC alone according to baseline flGF-I levels. (B) A hazard ratio of patients receiving treatment with PCF (I0 or $20 \mathrm{mg} \mathrm{kg}^{-1}$ ) vs PC alone according to baseline insulin to IGFBP-I ratio.

by fIGF-1 quartiles further indicated that clinical benefit of F combination therapy increased with baseline fIGF-1 levels. Tumours in patients with plasma fIGF-1 levels at the highest quartile (4th quartile, fIGF-1 $\geqslant 1 \mathrm{ng} \mathrm{ml}^{-1}$ ) derived particular benefit from the addition of $\mathrm{F}$ to standard chemotherapy (Figure 4).

\section{Effect of the insulin to IGFBP-1 ratio}

The findings described above prompted us to investigate the mechanisms underlying the heterogeneity of fIGF-1 levels among NSCLC patients. It is well known that the bioactivity of IGF-1 and IGF- 2 is modulated by 6 , potentially 7 , binding proteins (IGFBPs), of which IGFBP-1 and -3 are the best characterised (Pollak, 2008). Using the Pearson's parametric correlation test, a significant inverse correlation was identified between pre-treatment fIGF-1 and IGFBP-1 levels $(\rho=-0.295, P=0.005)$, but no significant association was observed between fIGF-1 and IGFBP-2 $(P=0.37)$ or IGFBP-3 $(P=0.9)$. Receiver operating characteristic plots were conducted to investigate potential associations between PFS rate and the pre-treatment ratios of IGF-1, IGF-2 and insulin to IGFBP$1,-2$ and -3 . A high baseline ratio of insulin $\left(\mu \mathrm{U} \mathrm{ml}^{-1}\right)$ to IGFBP-1 $\left(\mathrm{ng} \mathrm{ml}^{-1}\right)$ was found to be predictive $(P=0.05-0.1)$ of the PFS rate of patients receiving PCF20 at multiple time points in the 3-8 months post-treatment period. No other significant associations were identified.

Insulin/IGFBP-1 ratio cutoffs criteria of $0.6-1$ were then examined using Cox proportional hazards models. For PCF20, all cutoff criteria appeared to be potentially useful, with one-sided $P$-values for treatment-biomarker interaction of 0.07 (insulin/ IGFBP-1 ratio of 0.5 ), 0.06 (ratio of 0.6 ), 0.02 (ratio of 0.7 ), 0.02 

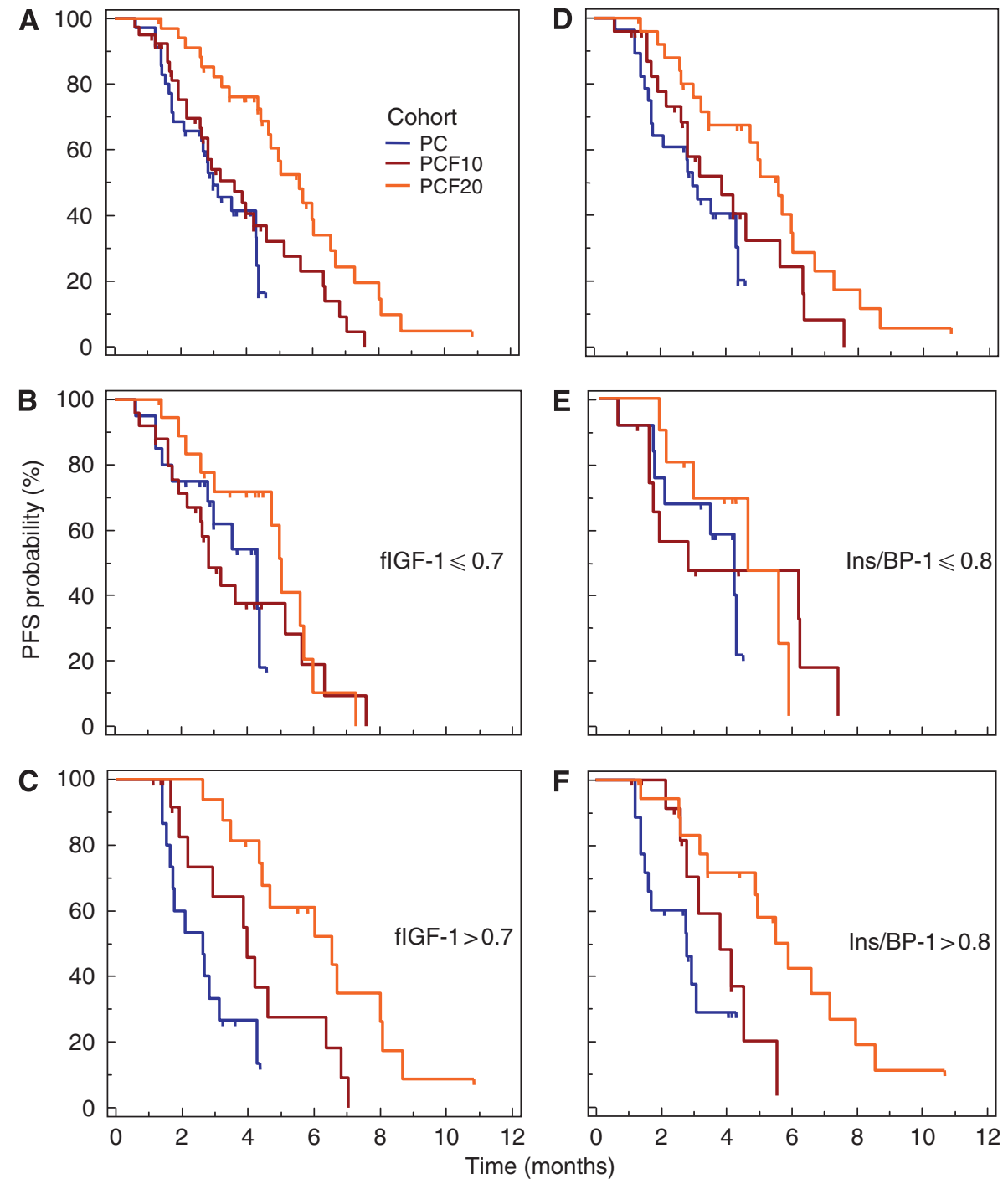

Figure 3 Kaplan-Meier plots of PFS in Study 1002 patients. (A) All patients with available baseline flGF-I level data $(N=|| 0)$. (B and C) Patients with baseline flGF-I $\leqslant 0.7(\mathbf{B}, N=64)$ or $>0.7 \mathrm{ng} \mathrm{ml}^{-1}(\mathbf{C}, N=46)$. (D) All patients with available baseline insulin/lGFBP-I ratio data ( $\left.N=82\right)$. $(\mathbf{E}$ and $\mathbf{F})$ Patients with baseline insulin/IGFBP-I ratio $\leqslant 0.7(\mathbf{E}, N=34)$ or $>0.7 \mathrm{ng} \mathrm{ml}^{-1}(\mathbf{F}, N=48)$.

(ratio of 0.8 ), 0.03 (ratio of 0.9 ), 0.01 (ratio of 1 ) and 0.08 (ratio of 1.1), respectively, adjusted for multiple testing (Figure 2B). For PCF10, cutoff criteria of interest were $0.9(P=0.04)$ and $1(P=0.05)$. Kaplan-Meier estimates of median PFS in patients enrolled in Study 1002 who had a baseline insulin/IGFBP-1 ratio above 0.8 were $2.83(\mathrm{PC}), 3.86$ (PC10) and 5.60 months (PC20), respectively $(P=0.016$; Figure $2 \mathrm{D}-\mathrm{F})$.

\section{Other potential predictors}

Other potential predictors of $\mathrm{F}$ activity were investigated. These included creatinine and creatine clearance, body mass index, fasting glucose to insulin ratio, the homeostatic model assessment of insulin sensitivity (HOMA) and the quantitative insulin sensitivity check index (QUICKI). None of these parameters reached significance in both the ROC and the Cox biomarker interaction analyses. A potential interaction with smoking was investigated using patient reported smoking habits and measuring pre-treatment cotinine levels, a serum metabolite of nicotine. Cotinine was detected in 0 of 13 patients who declared to have never smoke, eight of 61 patients who declared to be ex-smokers and 12 of 17 smokers. No effect of cotinine levels or smoking status on the PFS of patients receiving $\mathrm{F}$ was identified.

\section{High plasma fIGF-1 is associated with high vimentin and low E-cadherin expression in NSCLC}

We have previously shown that the IGF-IR and other molecules associated to the IGF-IR pathway (e.g. IGF-2R, IRS-1, -2) are overexpressed in NSCLC tumours undergoing epithelial-tomesenchymal transition (EMT) (Gualberto et al, 2009). Epithelial-to-mesenchymal transition is a key feature of tumour infiltration and metastasis that is characterised at a molecular level by the expression of mesenchymal markers, such as vimentin, and the downregulation of epithelial differentiation markers, such as E-cadherin (Kalluri and Weinberg, 2009). We hypothesised that high circulating levels of fIGF-1 could be associated with high IGF bioactivity in the tumour microenvironment, and this could favour EMT. As a first step investigating the relationship between fIGF-1 in plasma and tumour EMT, E-cadherin and vimentin levels were 
quantified using F-IHC in tumour biopsies of 45 patients enrolled in Study 1002. The relationship between circulating fIGF-1 and tissue marker expression (F-IHC AQUA scores) was investigated using Pearson's correlation analysis. Free IGF-1 correlated directly with tumour vimentin $(\rho=0.594 ; P=0.021)$, and inversely with E-cadherin expression $(\rho=-0.389 ; P=0.152)$ and the tumour E-cadherin/vimentin ratio $(\rho=-524, P=0.007)$. Of note, tumours in patients who had high levels of circulating fIGF-1 had barely detectable levels of E-cadherin (Figure 5), suggesting high degree of tissue de-differentiation.

\section{DISCUSSION}

Many targeted therapies are active only for a subset of patients, and the characterisation of predictive biomarkers to identify those

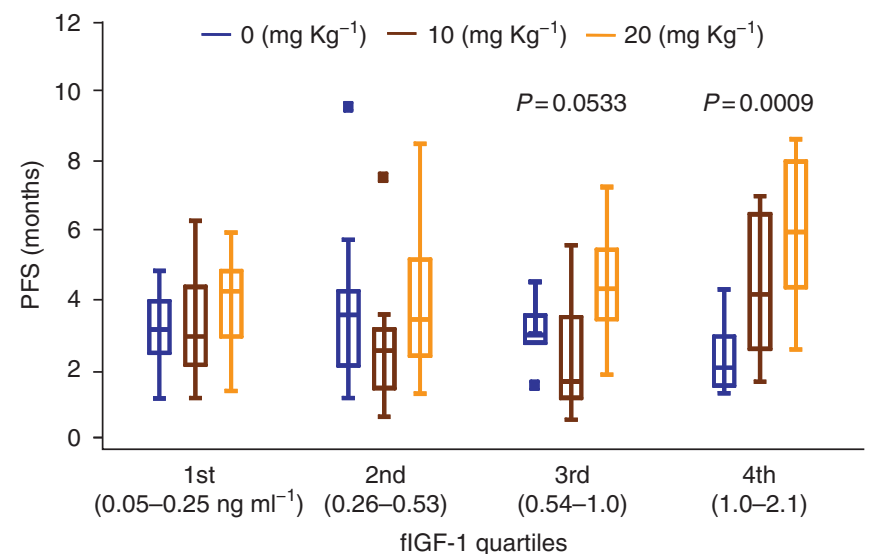

Figure 4 Progression-free survival of PC, PCFIO and PCF2O patients by flGF-I quartile. The central box represents the values from the lower to upper quartile (25-75 percentile). In the box plots, the middle line represents the median. $A$ line extends from the minimum to the maximum value, excluding 'outside' values that are displayed as separate points. An outside value is defined as a value that is smaller than the lower quartile minus 1.5 times the interquartile range, or larger than the upper quartile plus 1.5 times the interquartile range (inner fences). These values are plotted with a square marker. patients who are likely to benefit has been a key aspect of drug development. Examples include predicting benefit from trastuzumab therapy in breast cancer by assessing HER2/neu amplification (Sauter et al, 2009) and from cetuximab in colorectal cancer by assessing $K$-ras mutations (Siena et al, 2009). To date, predictive biomarkers for targeted therapies in NSCLC have been defined largely in the context of agents that target the EGF receptor family (Shepherd and Tsao, 2010), although recent data suggest a predictive value of $E M L 4-A L K$ gene fusion for the clinical benefit derived from ALK inhibition (Koivunen et al, 2008). We undertook the current investigation to identify potential biomarkers that would allow for the prospective selection of patients who could benefit from the addition of $\mathrm{F}$ to standard chemotherapy of NSCLC.

Higher pre-treatment fIGF-1 levels were found to be predictive of the clinical benefit derived from the addition of $F$ to chemotherapy in NSCLC patients. Although these results require confirmation in larger studies, it is of interest that consistent with our results, preliminary data from a recently discontinued phase III of PCF20 vs PC in patients with non-adenocarcinoma NSCLC revealed a biomarker/treatment interaction for baseline levels of fIGF-1. Median overall survival times were 10.2 and 7.0 months, respectively, for patients with a baseline fIGF1 $>1 \mathrm{ng} \mathrm{m}^{-1}$ receiving PCF20 and PC alone (Jassem et al, 2010). Analysis of this phase III study continues and final results will be discussed elsewhere.

In view of the considerable interindividual heterogeneity in levels of IGFs and their binding proteins, we hypothesise that plasma hormone levels might have particular utility in personalised therapy. This is a departure from the more common paradigm of emphasising molecular characteristics of the tumour in searching for predictive biomarkers. The reasoning underlying this hypothesis is that tumours that develop in a patient with high IGF bioactivity are more likely to become dependent on (or even 'addicted' to) IGF-1 receptor signalling, and therefore may be more sensitive to $\mathrm{F}$ therapy. Our results suggest that pre-treatment levels of fIGF-1 are predictive of the clinical benefit of $\mathrm{F}$ therapy in NSCLC, independent of any tumour characteristics. The possibility that more precise identification of patients who may benefit from IGF-IR targeting could be achieved by the use of algorithms that combines patient hormone levels and tumour characteristics remains open, but could not be explored in this study owing to
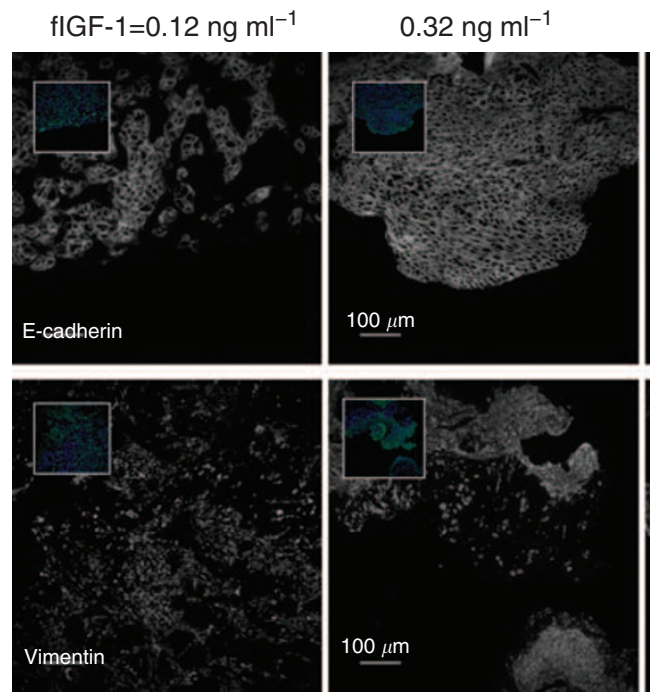

Patient 1

Patient 2
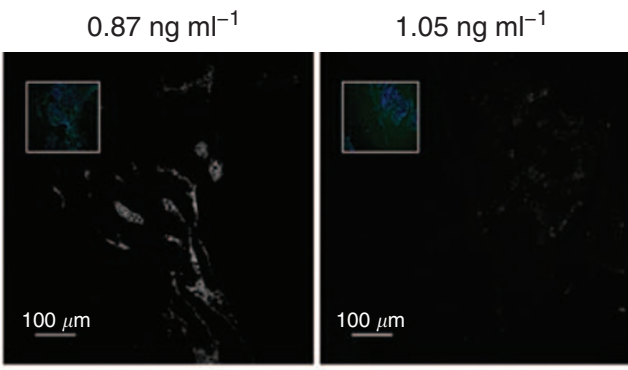

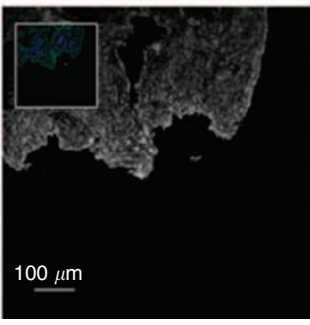

Patient 3

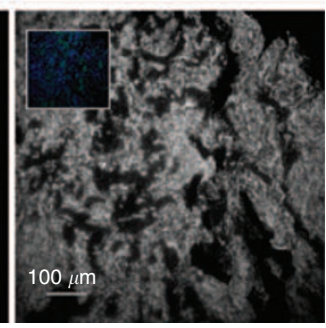

Patient 4

Figure 5 Cyanine-5 fluorescence images representative of vimentin and E-cadherin expression in tumours from Study 1002 patients. Insets show cytokeratin (green) and DAPI (blue) fluorescence sample stainings. 
small sample size. We observed however that tumours of patients with elevated circulating fIGF-1 expressed higher levels of vimentin and lower levels of E-cadherin, suggesting EMT. We speculate that this tumour characteristic is secondary to the hormonal environment. It has been shown previously that IGFs can induce neo-expression of mesenchymal markers and E-cadherin downregulation (reviewed by Julien-Grille et al (2005)). Insulin growth factors have also been shown to enhance the phosphorylation of $\beta$-catenin, causing its dissociation from membrane E-cadherin and translocation to the cytoplasm/nucleus (Playford et al, 2000; Morali et al, 2001). These interactions are thought to facilitate the coupling of IGF-IR activation with migration, invasiveness and metastasis.

High insulin to IGFBP-1 ratio was also predictive of the clinical benefit derived from $\mathrm{F}$ therapy, and an inverse correlation was observed between fIGF-1 and IGFBP-1. A role for IGFBP-1 in the control of IGF-1 bioactivity has been described previously (Bereket et al, 1996; Attia et al, 1999). Of note, over 90\% of serum IGF-1 circulates in a complex with IGFBP-3 and another glycoprotein, acid-labile subunit (ALS). This complex is large $(150 \mathrm{kDa})$, unable to transverse the endothelial barrier and has a long half-life, acting as a serum reservoir of IGF-1 (Kelley et al, 1996). In contrast, IGF-1 bound to IGFBP-1 does not form complexes with ALS, is able to cross the endothelial barrier and is, consequently, more likely to play a role in the regulation of IGF-1 bioactivity at extravascular tissues (Lee et al, 1993).

Insulin growth factor binding protein-1 levels and its IGF-1 binding capacity are tightly regulated by insulin, with IGFBP-1, as a result, acting as a bridging molecule between the insulin and IGF systems (Sakai et al, 2001; Borai et al, 2007). Thus, our data suggest that insulin may affect the risk/benefit of anti-IGF-IR therapy by regulating fIGF-1 levels. This is not in contradiction with other potential effects of insulin on cancer therapy; for example, those mediated by insulin receptors on tumour cells (Gualberto and Pollak, 2009). A role for IGFBP-1 in cancer has not been extensively studied, but it is known that low IGFBP-1 levels are associated with poor prognosis in at least one tumour type, colorectal cancer (Wolpin et al, 2009). Further research on IGFBP1 functions could contribute to a better understanding of the effects of carbohydrate metabolism on cancer outcome. Overall, our data are consistent with previous reports associating low IGF-1 bioactivity with longer overall, disease-free and event-free survival in NSCLC (Chang et al, 2002; Han et al, 2006). In principle, the utilisation of circulating factors as predictive biomarkers would appear to be more convenient than measurements requiring fresh or frozen neoplastic tissue. However, it should be noted that current assay methodologies, particularly those measuring IGF-1 bioactivity, are controversial and imperfect (Frystyk, 2007). For example, in some applications, measurement of fIGF-1 offers no additional information beyond that provided by total IGF-1 (Juul et al, 1997), a measurement which is much more widely used than fIGF-1, but that is itself challenging (Brugts et al, 2008a). This issue is further complicated by the relatively small fraction of total IGF-1 bound to IGFBP-1 (Attia et al, 1999). In our hands, the fIGF-1 assay had an intra-assay imprecision of approximately $10 \%$ at the criteria of interest $\left(0.5-0.9 \mathrm{ng} \mathrm{m}^{-1}\right)$; however, differences were observed across reagent lots. Thus, further analytical validation would be desirable before the prospective use of this assay in randomised studies. Structural studies have recently shown that the binding residues for IGFBP-1 and -3 on IGF-1 are overlapping but distinct (Dubaquié and Lowman 1999; Dubaquié et al, 2001). These differences could be exploited to develop new assays for the quantification of the fIGF-1 fraction specifically released from IGFBP-1. Development of such reagents could be important for a more personalised use of anti-IGF-IR therapy.

This exploratory study was not sufficiently powered for subset safety analysis. No major differences in the frequency or severity of adverse events between subgroups of patients with low vs high baseline fIGF-1 were apparent (not shown). Low levels of IGF-1 bioactivity have been associated with increased risk of cardiovascular mortality, whereas fasting IGFBP-1 levels were associated with more favourable cardiovascular risk profiles (Janssen et al, 1998; Brugts et al, 2008b). Of note, IGF-1 bioactivity changes during the progression of the metabolic syndrome, increasing in parallel to HOMA-IR and hyperinsulinaemia, but decreasing drastically when patients reach frank diabetes (Brugts et al, 2010). Insulin growth factor-1 bioactivity is also limited at low total IGF-1 levels (Brugts et al, 2010). Thus, treatment with anti-IGF-IR therapy in patients with low levels of total IGF-1 and/or glucose intolerance should be approached with caution. The ongoing analysis of the safety profile of larger $\mathrm{F}$ studies may contribute to a better understanding of the potential role of fIGF-1 in the assessment of the risk/benefit of anti-IGF-IR therapy.

In conclusion, our data provide preliminary evidence that fIGF-1 is a predictive biomarker of the clinical benefit, in terms of PFS, of $\mathrm{F}$ therapy in NSCLC. Confirmation of these findings in larger studies is needed. We also recognise the need to optimise assay methods and to further study the interactions between serum markers and tumour characteristics in NSCLC and other cancer types in which IGF-IR targeting is currently being investigated.

\section{ACKNOWLEDGEMENTS}

We thank our patients for their participation in this trial. This work was supported in part by NIH PHS Grants ES015704 (to $\mathrm{MLH})$, and by Pfizer Inc.

\section{REFERENCES}

Attia N, Caprio S, Jones TW, Heptulla R, Holcombe J, Silver D, Sherwin RS, Tamborlane WV (1999) Changes in free insulin-like growth factor-1 and leptin concentrations during acute metabolic decompensation in insulin withdrawn patients with type 1 diabetes. J Clin Endocrinol Metab 84: $2324-2328$

Bereket A, Lang CH, Blethen SL, Ng LC, Wilson TA (1996) Insulin treatment normalizes reduced free insulin-like growth factor-I concentrations in diabetic children. Clin Endocrinol (Oxf) 45: 321-326

Borai A, Livingstone C, Ferns GA (2007) The biochemical assessment of insulin resistance. Ann Clin Biochem 44: 324-342

Brugts MP, Ranke MB, Hofland LJ, van der Wansem K, Weber K, Frystyk J, Lamberts SW, Janssen JA (2008a) Normal values of circulating insulinlike growth factor-I bioactivity in the healthy population: comparison with five widely used IGF-1 immunoassays. J Clin Endocrinol Metab 93: $2539-2545$

Brugts MP, van den Beld AW, Hofland LJ, van der Wansem K, van Koetsveld PM, Frystyk J, Lamberts SW, Janssen JA (2008b) Low circulating insulinlike growth factor I bioactivity in elderly men is associated with increased mortality. J Clin Endocrinol Metab 93: 2515-2522

Brugts MP, van Duijn CM, Hofland LJ, Witteman JC, Lamberts SW, Janssen JA (2010) Igf-I bioactivity in an elderly population: relation to insulin sensitivity, insulin levels, and the metabolic syndrome. Diabetes 59: 505-508

Chang YS, Kong G, Sun S, Liu D, El-Naggar AK, Khuri FR, Hong WK, Lee HY (2002) Clinical significance of insulin-like growth factor-binding protein-3 expression in stage I non-small cell lung cancer. Clin Cancer Res 8: $3796-3802$ 
Chitnis MM, Yuen JS, Protheroe AS, Pollak M, Macaulay VM (2008) The type 1 insulin-like growth factor receptor pathway. Clin Cancer Res 14: $6364-6370$

Cohen BD, Baker DA, Soderstrom C, Tkalcevic G, Rossi AM, Miller PE, Tengowski MW, Wang F, Gualberto A, Beebe JS, Moyer JD (2005) Combination therapy enhances the inhibition of tumor growth with the fully human anti-type 1 insulin-like growth factor receptor monoclonal antibody CP-751,871. Clin Cancer Res 11: 2063-2073

Dubaquié Y, Lowman HB (1999) Total alanine-scanning mutagenesis of insulin-like growth factor I (IGF-1) identifies differential binding epitopes for IGFBP-1 and IGFBP-3. Biochemistry 38: 6386-6396

Dubaquié Y, Mortensen DL, Intintoli A, Hogue DA, Nakamura G, Rancatore P, Lester P, Sadick MD, Filvaroff E, Fielder PJ, Lowman HB (2001) Binding protein-3-selective insulin-like growth factor I variants: engineering, biodistributions, and clearance. Endocrinology 142: $165-173$

Favoni RE, de Cupis A, Ravera F, Cantoni C, Pirani P, Ardizzoni A, Noonan D, Biassoni R (1994) Expression and function of the insulin like growth factor 1 system in human non small cell lung cancer and normal lung cell lines. Int J Cancer 56: 858-866

Frystyk J (2007) Utility of free IGF-1 measurements. Pituitary 10: 181 - 187

Gualberto A (2010) Figitumumab (CP-751,871) for cancer therapy. Expert Opin Biol Ther 10: 575-585

Gualberto A, Dolled-Filhart MP, Hixon ML, Christensen J, Rimm DL, Lee AV, Wang Y, Pollak M, Paz-Ares LG, Karp DD (2009) Molecular basis for sensitivity to figitumumab (CP-751,871) in NSCLC. J Clin Oncol 27: 15s (abstract 8091)

Gualberto A, Pollak M (2009) Emerging role of insulin-like growth factor receptor inhibitors in oncology: early clinical trial results and future directions. Oncogene 28: 3009-3021

Han JY, Choi BG, Choi JY, Lee SY, Ju SY (2006) The prognostic significance of pretreatment plasma levels of insulin-like growth factor (IGF)-1, IGF-2, and IGF binding protein-3 in patients with advanced non-small cell lung cancer. Lung Cancer 54: 227-234

Janssen JA, Stolk RP, Pols HA, Grobbee DE, Lamberts SW (1998) Serum total IGF-1, free IGF-1, and IGFB-1 levels in an elderly population: relation to cardiovascular risk factors and disease. Arterioscler Thromb Vasc Biol 18: 277-282

Jassem J, Langer CJ, Karp DD, Mok T, Benner RJ, Green SJ, Park K, Novello S, Strausz J, Gualberto A (2010) Randomized, open label, phase III trial of figitumumab in combination with paclitaxel and carboplatin versus paclitaxel and carboplatin in patients with non-small cell lung cancer (NSCLC). J Clin Oncol 28: 15s (abstract 7500)

Julien-Grille S, Moore R, Denat L, Morali OG, Delmas V, Bellacosa A, Laure L (eds) (2005) The role of insulin-like growth factors in the epithelial to mesenchymal transition. In: Rise and Fall of Epithelial Phenotype: Concepts of Epithelial. Eurekah/Landes Bioscience: Georgetown

Juul A, Holm K, Kastrup KW, Pedersen SA, Michaelsen KF, Scheike T, Rasmussen S, Müller J, Skakkebaek NE (1997) Free insulin-like growth factor I serum levels in 1430 healthy children and adults, and its diagnostic value in patients suspected of growth hormone deficiency. $J$ Clin Endocrinol Metab 82: 2497-2502
Kalluri R, Weinberg RA (2009) The basics of epithelial-mesenchymal transition. J Clin Invest 119: 1420-1428

Karp DD, Paz-Ares LG, Novello S, Haluska P, Garland L, Cardenal F, Blakely LJ, Eisenberg PD, Langer CJ, Blumenschein Jr G, Johnson FM, Green S, Gualberto A (2009) Phase II study of the anti-insulin-like growth factor type 1 receptor antibody CP-751,871 in combination with paclitaxel and carboplatin in previously untreated, locally advanced, or metastatic non-small-cell lung cancer. J Clin Oncol 27: $2516-2522$

Kelley KM, Oh Y, Gargosky SE, Gucev Z, Matsumoto T, Hwa V, Ng L, Simpson DM, Rosenfeld RG (1996) Insulin-like growth factor-binding proteins (IGFBPs) and their regulatory dynamics. Int J Biochem Cell Biol 28: $619-637$

Koivunen JP, Mermel C, Zejnullahu K, Murphy C, Lifshits E, Holmes AJ, Choi HG, Kim J, Chiang D, Thomas R, Lee J, Richards WG, Sugarbaker DJ, Ducko C, Lindeman N, Marcoux JP, Engelman JA, Gray NS, Lee C, Meyerson M, Jänne PA (2008) EML4-ALK fusion gene and efficacy of an ALK kinase inhibitor in lung cancer. Clin Cancer Res 14: 4275-4283

Lee PD, Conover CA, Powell DR (1993) Regulation and function of insulinlike growth factor binding protein-1. Proc Soc Exp Biol Med 204: 4-29

Morali OG, Delmas V, Moore R, Jeanney C, Thiery JP, Larue L (2001) IGF-2 induces rapid beta-catenin relocation to the nucleus during epithelium to mesenchyme transition. Oncogene 20: $4942-4950$

Sakai K, D'Ercole AJ, Murphy LJ, Clemmons DR (2001) Physiological differences in insulin-like growth factor binding protein-1 (IGFBP-1) phosphorylation in IGFBP-1 transgenic mice. Diabetes 50: $32-38$

Playford MP, Bicknell D, Bodmer WF, Macaulay VM (2000) Insulin-like growth factor 1 regulates the location, stability, and transcriptional activity of beta-catenin. Proc Natl Acad Sci USA 9: 12103-12108

Pollak M (2008) Insulin and insulin-like growth factor signalling in neoplasia. Nat Rev Cancer 8: $915-928$

Siena S, Sartore-Bianchi A, Di Nicolantonio F, Balfour J, Bardelli A (2009) Biomarkers predicting clinical outcome of epidermal growth factor receptor-targeted therapy in metastatic colorectal cancer. J Natl Cancer Inst 101: $1308-1324$

Sauter G, Lee J, Bartlett JM, Slamon DJ, Press MF (2009) Guidelines for human epidermal growth factor receptor 2 testing: biologic and methodologic considerations. J Clin Oncol 27: 1323-1333

Shepherd FA, Tsao MS (2010) Epidermal growth factor receptor biomarkers in non-small-cell lung cancer: a riddle, wrapped in a mystery, inside an enigma. J Clin Oncol 28: 903-905

Spitz MR, Barnett MJ, Goodman GE, Thornquist MD, Wu X, Pollak M (2002) Serum insulin like growth factor (IGF) and IGF binding protein levels and risk of lung cancer: a case control study nested in the beta carotene and retinol efficacy trial cohort. Cancer Epidemiol Biomarkers Prev 11: 1413 - 1418

Wolpin BM, Meyerhardt JA, Chan AT, Ng K, Chan JA, Wu K, Pollak MN, Giovannucci EL, Fuchs CS (2009) Insulin, the insulin-like growth factor axis, and mortality in patients with nonmetastatic colorectal cancer. 27: $176-185$

Zweig MH, Campbell G (1993) Receiver-operating characteristic (ROC) plots: a fundamental evaluation tool in clinical medicine. Clin Chem 39: 561 - 577 


\section{Retraction}

\section{Pre-treatment levels of circulating free IGF-I identify NSCLC patients who derive clinical benefit from figitumumab}

\section{A Gualberto, ML Hixon, DD Karp, D Li, S Green, M Dolled-Filhart, LG Paz-Ares, S Novello, J Blakely, CJ Langer and MN Pollak}

British Journal of Cancer (2012) 1 07, 2024. doi:I0.1038/bjc.2012.497 www.bjcancer.com

(c) 2012 Cancer Research UK

Retraction to: British Journal of Cancer (2011) 104, 68-74. doi: $10.1038 /$ sj.bjc.6605972

After a thorough review, the corresponding author, Dr Antonio Gualberto, has concluded that the key results reported in this manuscript are incorrect and cannot be reproduced. As there are no remaining samples that would allow a new analysis, he has therefore recommended the retraction of the manuscript to the Editor-in-Chief of BJC.

The co-authors have been informed of this decision.

Dr Gualberto sincerely apologises for any inconvenience this may have caused the readers of the BJC. 